\title{
Awareness on Organ and Body Donation Among Dental and Medical Students
}

\author{
Bipin Maheshwaran ${ }^{1}$, Thenmozhi M.S ${ }^{2}$ and S.Sangeetha ${ }^{3}$ \\ ${ }^{1}$ Saveetha Dental College and Hospitals, Saveetha Institute of Medical \\ and technical Sciences, Saveetha University, Chennai - 600077, India \\ ${ }^{2}$ Professor, Department of Anatomy Saveetha Dental College and Hospitals, \\ Saveetha Institute of Medical and technical Sciences, Saveetha University, \\ Chennai - 600077, India \\ ${ }^{3}$ Lecturer, Department of Anatomy Saveetha Dental College and Hospitals, \\ Saveetha Institute of Medical and technical Sciences, Saveetha University, \\ Chennai - 600077, India
}

\section{ABSTRACT}

Cadaveric donation comprises body donation, organ donation that is, taking out organs (heart, lungs, kidneys, liver, pancreas) from brain dead people, as well as tissue donation, meaning taking tissues (skin, corneas, tendons, bone) from brain dead as well as heart dead people.In a broader sense, however, pathologists are involved in cadaveric tissue donation as well as taking tissues from cadavers for diagnostic procedures within the framework of the autopsy (fluids, organs, tissue samples), and to gather material for research and training students and pathology residents (tissues, organs). For cadaveric tissue donation, different ethical and practical issues must be considered, which we will try to review in this paper from the perspective of the pathologist. It is possible to donate your body to medical science after your death. To make the arrangements, contact the anatomical institute of one of the universities in India , as this is a separate process to organ or tissue donor registration. The aim of the study is to evaluate the knowledge and awareness of organ donation. Analytic, longitudinal and quantitative study, conducted in 5 Medical/Dental College in Natal/RN, between November 2019 and January 2020. Survey has been conducted among dental and medical students 105 responses have been received from 5 medical and dental colleges. Regarding the donation structure, there were deficiencies of physical resources (temperature control), materials (mobile radiology), human resources (nurse technicians) and lack of adequate records and care protocols. In the process of donation, the biggest problems were related to the evaluation stages, brain death diagnosis, maintenance and documentation, with greater proportion of care for the non-donor. $85.4 \%$ of the respondents were aware of Organ donation whereas $14.6 \%$ of the study population were not aware about organ donation. The primary outcome was intention to donate. Taking a donor card after the interview was a secondary behavioral outcome.

KEY WORDS: BRAIN DEATH, CADAVERIC TISSUE, DONATION, GRAFT REJECTION, TRANSPLANTATION.

\section{ARTICLE INFORMATION}

*Corresponding Author: sangeethas.sdc@saveetha.com

Received 5th Aug 2020 Accepted after revision 22nd Sep 2020

Print ISSN: 0974-6455 Online ISSN: 2321-4007 CODEN: BBRCBA

Thomson Reuters ISI Web of Science Clarivate Analytics USA and Crossref Indexed Journal

$$
\begin{aligned}
& \text { Clarivate } \\
& \text { Analytics }
\end{aligned}
$$




\section{INTRODUCTION}

Organ transplantation is the most favored treatment methodology for patients with end-stage organ malady. The need for organ transplantation is higher than the necessity(Allen and Stillwater, no date; Ganikos, no date; Sarti, 1999; Ahlert and Sträter, 2020) For the transplantation program to be fruitful, mindfulness with respect to organ donation is required and individuals must have an inspirational disposition toward giving organs(Magotra, 2014; Bashir, 2017; Kumar, Kanvinde and Thomas, 2018; Akbulut et al., 2020). While patients with end stage renal disease can be treated by other renal replacement therapies, kidney transplantation is widely recognized as the best cure for both quality of life and cost effectiveness(Organ Donation and Transplantation: Awareness and Roles of Healthcare Professionals-A Systematic Literature Review, 2018; Alan and Kurt, 2019; Ismail, Lim and Mahadevan, 2020).

In fact, Kidney transplantation is considered to be the most frequent transplants to be carried out globally(Ponticelli, 2007; Gulec, 2011; Orlando, Remuzzi and Williams, 2017). The acquisition of organs for transplantation includes the removal of organs from the bodies of the dead(Petechuk, 2006; Tsoulfas, 2018; Kruci冈ska et al., 2020). This removal must meet legal criteria, including the death and consent concepts. Although organ transplantation was initially limited to the transplantation of vital organs, today medical and surgical processes have been developed to allow the transplantation of a number of organs that not only allow longer lifespans, but also improve the quality of life of the patient.

Organ donation includes heart, pancreas, lung, liver, cornea, kidney, trachea, skin transplants. Owing to the lack of organs, heart transplants are one of the most important and least conducted organ transplant operations, although only few are done annually. Even the lung transplants still remain uncommon owing to shortage of donors. For cases of chronic liver disease, the unhealthful liver of the patient is removed and replaced by either a part of the liver from a living donor, such as a friend, or a whole healthy liver from a deceased donor(Fan, Chiu and Hui, 2011; 'Liver Transplantation', 2016; Ponziani et al., 2020; Rinehardt et al., 2020). Endstage liver disease, particularly cirrhosis of the liver due to alcohol abuse, is the most common reason for liver organ transplant surgery(Bhamidimarri, 2014; Busuttil and Klintmalm, 2015; Humar and Tevar, 2018).

Kidney and pancreas double transplant is the most common transplant in case of pancreas replacement. Type 1 diabetes causing kidney failure is one of the major reasons for this type of transplant. In this case, the kidney is obtained from a healthy living donor whereas the pancreas is obtained from the deceased donor(Toledo-Pereyra, 2012; Troppmann, 2020). Scarring from eye infections such as keratitis or herpes, and other eye diseases such as keratoconus where the shape of the cornea is distorted are some reasons for corneal
transplantation(Mannis, 2004; Singh and Tripathy, 2016). Renal disease affects the large group of population today.

The kidney is an integral part of the human system , that helps to flush out blood toxins and maintain an electrolyte equilibrium that allows the body to function naturally. Organ transplants require psychological, financial, mental as well as physical preparation. It is very much essential to cultivate patients with a positive attitude and awareness about their state of health('Organ Transplants and Ethics', 1992; Schwartz, 2005; Al-Khafaji, 2017). Usually the transplantation is carried out with the help of certain drugs to prevent graft rejection. As the major problem of the transplantation seems to be graft rejection, the body's immune system automatically rejects the foreign tissue. Some of the immunosuppressant drugs are being used to prevent such types of rejections (Busker, 1988; Critchley and Fildes, 2012; Afzali, Lechler and Lombardi, 2015).

Although the quality of life for a patient after a successful organ transplant operation is increased, they continue to take many steps on a regular basis, often including a lifestyle adjustment. In addition to a prescription regimen, patients may need to monitor their activities, so higher or lower physical exercise rates can be recommended based on their doctor's recommendation. Some people are interested in cadaver donation as they come up with an agreement provided by the organisations(Boscolo-Berto et al., 2020; Hutchinson et al., 2020). Here in accordance with anyone's interest, cadaver donation is acceptable with terms and conditions.

Written and witnessed consent for anatomical examination has to be given prior to death under the Human Tissue Act 2004(Copeman, 2006; Patwardhan and Kulkarni, 2011; Siripurapu and Vijay Kumar Sharma, 2018). Body donations are highly valuable for many purposes that include anatomical examinations, research purpose, education and training. The aim of the study is to evaluate the knowledge and awareness on organ and body donation among medical and dental students. Previously we have done so many bioinformatics studies(Sekar et al., 2019; Johnson et al., 2020), morphological and morphometric studies(Choudhari and Thenmozhi, 2016; Hafeez and Thenmozhi, 2016; Kannan and Thenmozhi, 2016; Keerthana and Thenmozhi, 2016; Krishna, Nivesh Krishna and Yuvaraj Babu, 2016; Pratha, Ashwatha Pratha and Thenmozhi, 2016; Subashri and Thenmozhi, 2016; Nandhini et al., 2018), in vivo animal experimental studies(Seppan et al., 2018) and other survey analysis and Review analysis(Samuel and Thenmozhi, 2015; Sriram, Thenmozhi and Yuvaraj, 2015; Thejeswar and Thenmozhi, 2015; Menon and Thenmozhi, 2016) led us to conduct awareness study over the past 5 years. The idea for this survey stemmed from the current interest in our community. This study is to evaluate and cross the knowledge and awareness among the adult population. Study primarily focuses on the purpose and principles of lockdown. 


\section{MATERIAL AND METHODS}

The study was done on medical and dental students. The subjects were taken from medical and dental schools in Chennai. A total of 105 students were requested to participate in the study. The subjects' age limit were considered to be from 17 years to 30 years where it comprised both male and female participants. The questionnaire had 13 items in it which was designed in such a way to evaluate the awareness and attitude towards organ and body donation. Assessment of the subject's awareness and attitude towards organ and body donation included the questions relating the basic knowledge and procedures of organ donation. The subjects were requested to respond to each item in the specific format given at the end of each item. All the participants were allowed to choose one of the given three to four choices for each item in the questionnaire. The datas were collected,tabulated and represented as pie charts.

\section{RESULTS AND DISCUSSION}

In this study 105 students from various institutions were allowed to participate in this study. 85.4\% of the respondents were aware of Organ donation whereas $14.6 \%$ of the study population were not aware about organ donation [Figure 1]. 64.7\% of the respondents thought organ donation is legal and ethical but, remaining $35.3 \%$ of the study population felt it is illegal [Figure 2]. 82.7\% felt it is possible to donate body to medical science after death whereas $17.3 \%$ felt body donation to medical science is not practicable [Figure 3]. $68 \%$ of the students were aware of organ transplantation whereas the remaining 32\% of them were not sure about organ transplantation [Figure 4]. 74\% of the respondents felt there is demand for organ transplantation process in India whereas 26\% of them felt there are sufficient organ transplantation has been done everyday [Figure 5]. 64.7\% of the respondents were aware of the term embalming whereas 35.3\% were not aware of the term embalming [Figure 6]. 81.6\% thought increasing awareness levels regarding brain death would improve organ donation [Figure 7].

Figure 1: Pie chart representing percentage distribution of awareness of organ donation where Purple colour represents "Yes" and blue colour "No". Majority of them were aware about organ donation.

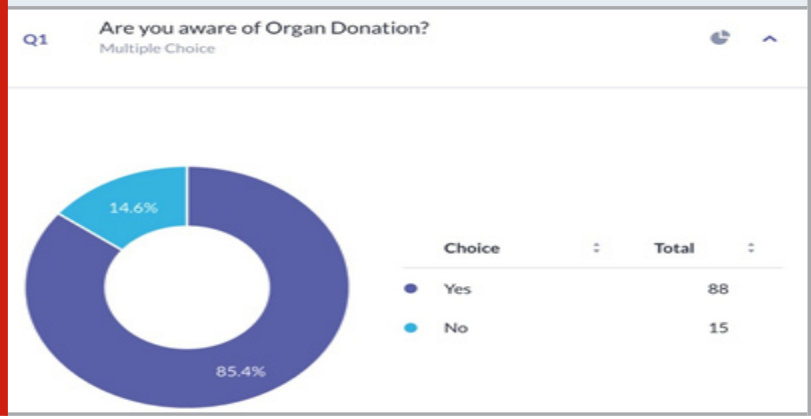

Figure 2: Pie chart representing percentage of distribution of awareness about ethical and legal issues in organ donation, where Purple colour represents "Yes" and blue colour represents "No". Majority of them were aware about the ethical and legal issues.

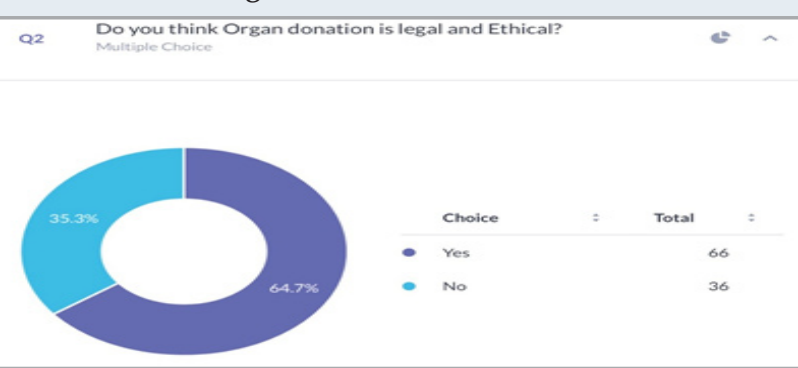

Figure 3: Pie chart representing percentage distribution of role of body donation in medical field, where Purple represents "Yes", blue colour represents "No". Majority of them were aware of body donation in the medical field.

Q3 Is that possible to donate your body to medical science after your death?

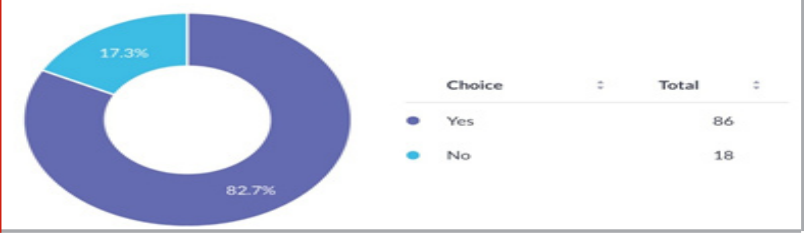

Figure 4: Pie chart representing the percentage distribution of awareness on organ transplantation where, purple colour represents "Yes", blue colour represents "No". Majority of them were aware about organ donation.

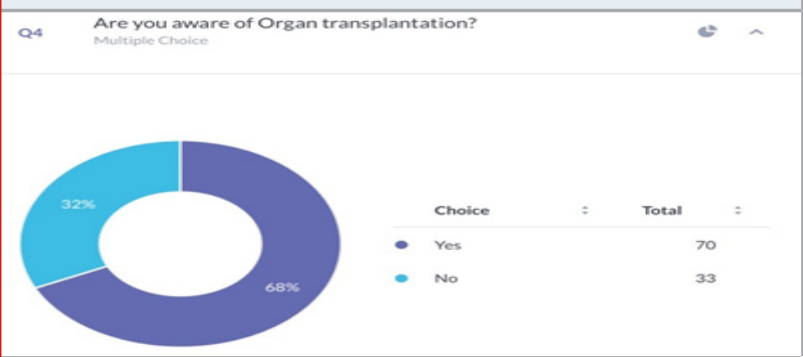

Figure 5: Pie chart representing the percentage distribution of awareness about demand in organ transplantation, where purple colour denotes "Yes" and blue colour denotes "No". Majority of them were aware of organ transplantation.

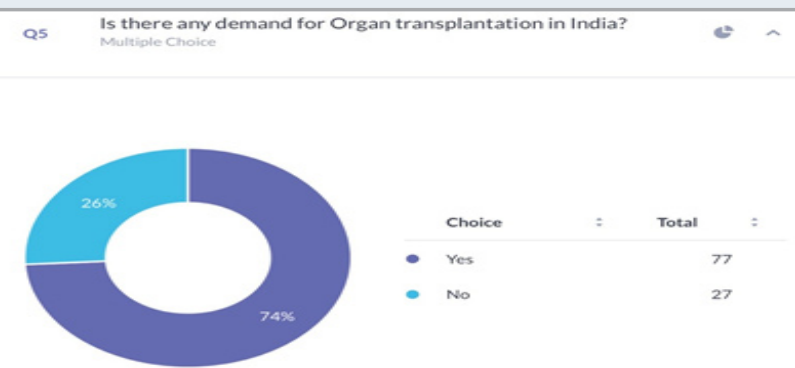


Figure 6: Pie chart representing the percentage distribution of awareness of term embalming, where purple colour denotes "Yes" and blue colour represents "No". Majority of them were aware of term embalming.

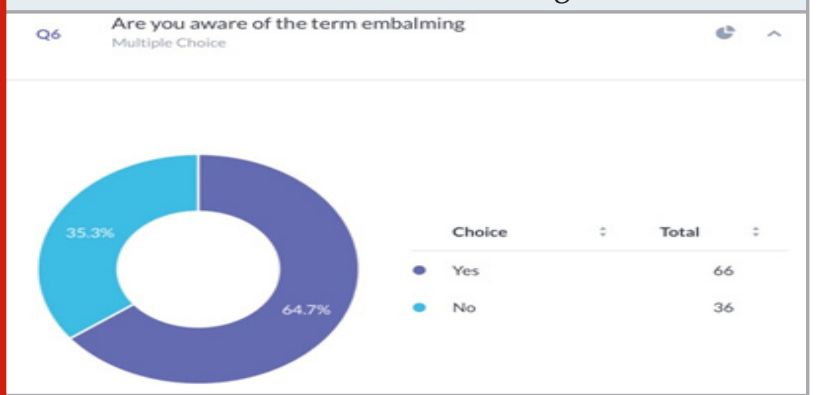

Figure 7: Pie chart representing the percentage distribution of awareness levels regarding brain death in organ donation, where purple colour represents "Yes" and blue colour represents "No". Majority of them were aware about brain death in organ donation.

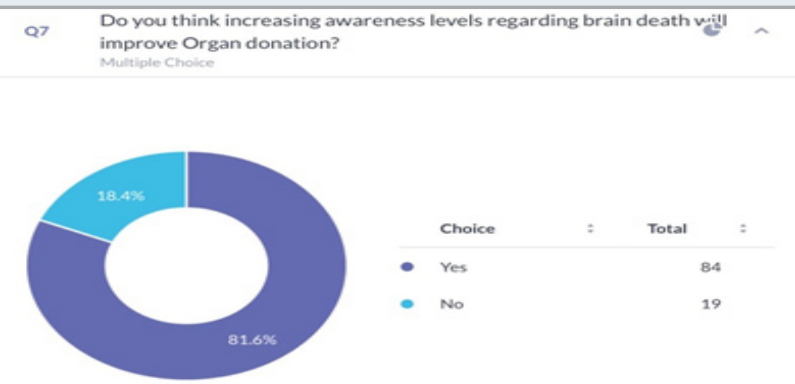

Figure 8: Pie chart representing the percentage distribution of knowledge on eligibility criteria in organ donation, where purple colour represents "Yes", blue colour represents "No". Majority of them were aware of eligibility criteria in organ donation.

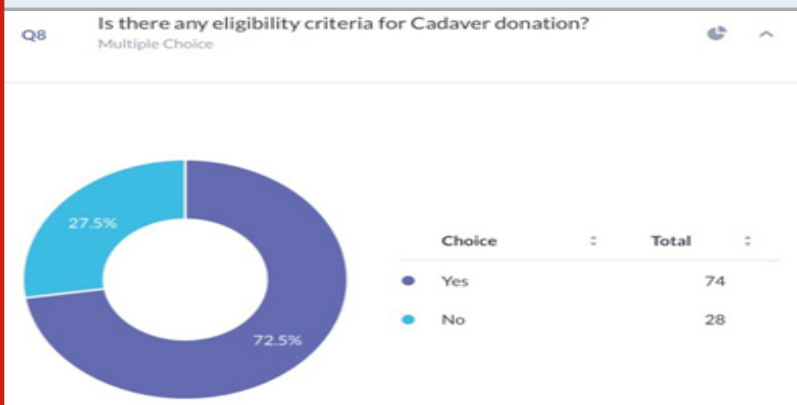

$72.5 \%$ felt there is an eligibility criteria for cadaver donation whereas $27.5 \%$ of the respondents denied the statement [Figure 8]. 68.3\% of the respondents felt that embalming procedure is done through arteries, $19.2 \%$ of the respondents felt that embalming is done through vein, $12.5 \%$ of the remaining participants felt embalming is done through nerves [Figure 9]. 61.4\% of them were aware of the procedures done in embalming whereas $38.6 \%$ of them were not aware of the procedures done in embalming [Figure 10]. 72.5\% of the students thought graft rejection would be the major drawback in organ transplantation whereas 27.5\% thought graft rejection would not be the major drawback in organ transplantation [Figure 11]. 61.5\% of them felt organ donation has been made to save someone's life. $29.8 \%$ of them felt that organ donation is done to make money, $8.7 \%$ of the remaining population considered organ donation as out of compassion [Figure 12].

Figure 9: Pie chart representing the percentage distribution of awareness about embalming conduction technique, where purple colour represents "Artery", blue colour represents "Vein" and green colour represents "Nerve". of them were aware that the artery was used during the procedure of embalming.

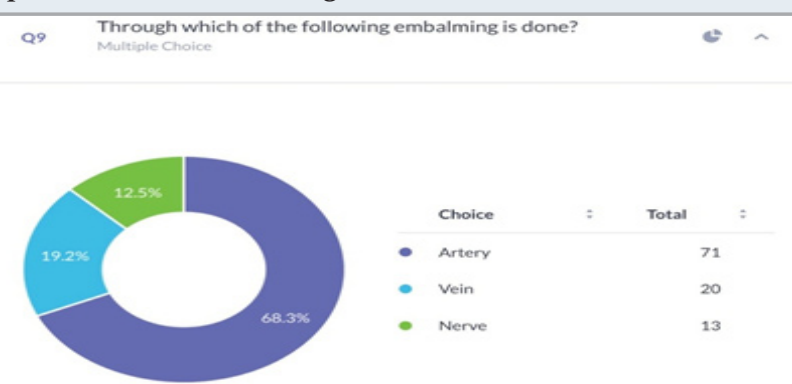

Figure 10: Pie chart representing the percentage distribution of awareness of procedures in embalming, where purple colour represents "Yes" and blue colour represents "No". Majority of them were aware of procedures in embalming.

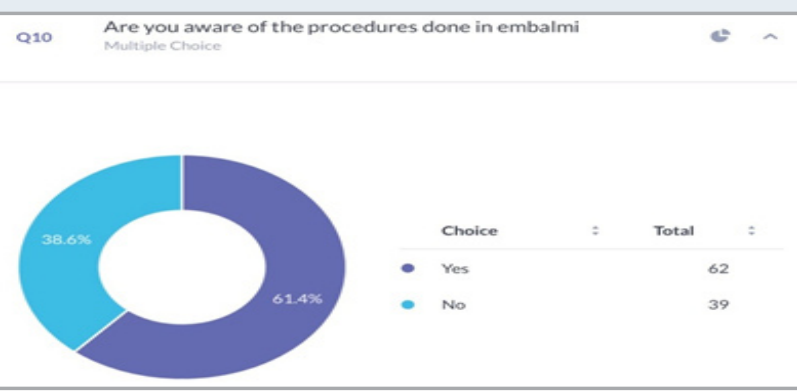

Figure 11: Pie chart representing the percentage distribution of awareness of graft rejection in organ transplantation where, purple colour represents "Yes" and blue colour represents "No". Majority of them were aware of graft rejection in organ transplantation.

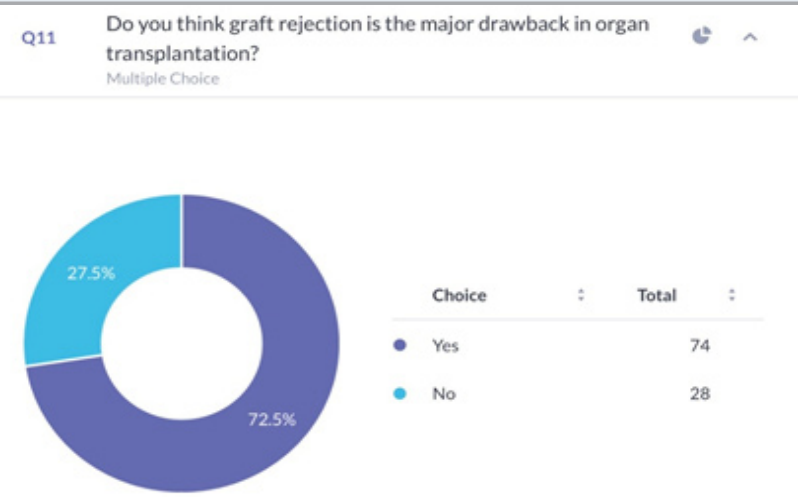


Figure 12: Pie chart representing the percentage distribution of awareness on reasons for organ donation, where purple colour represents "To save someone's life", blue colour represents "For Money", green colour represents "Out of compassion". Majority of them felt the reason for organ transplantation would be saving someone's life.

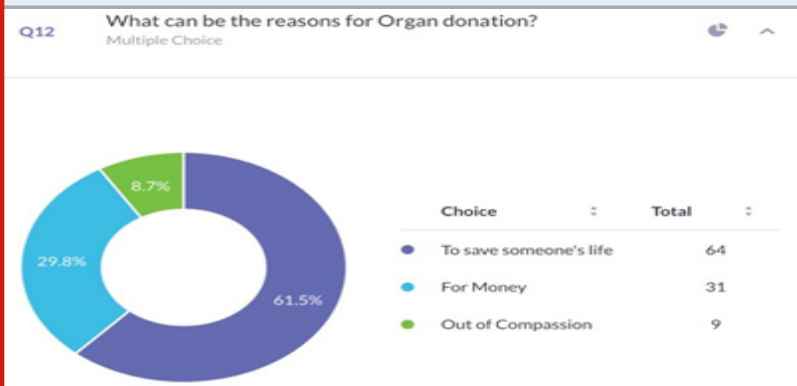

Figure 13: Pie chart representing the percentage distribution of awareness of major organs involved in organ transplantation where, purple colour represents "kidney", blue colour represents "skin", green colour represents "eye", yellow colour represents "heart". Majority of them were aware that the kidney would be the major organ that takes part in organ transplantation.

Q13 Which is the major organ involved in Organ Transplantation?
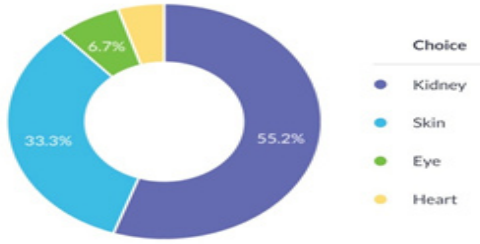

$55.2 \%$ of the study population believed that kidney would be the major organ involved in organ transplantation, $33.3 \%$ of the respondents felt skin would be the major organ involved in organ transplantation, 6.7\% of the remaining population felt that eye would be the major organ involved in organ transplantation [Figure 13]. From the above results we came to know that the dental and medical students have the awareness about organ transplantation and their importance. The study carried out by Priyadarshini B et al the incidence of awareness regarding eye donation was reported to be $50 \%$ and another study has reported much more than $72 \%$.

The study which is carried out in Hubli city of Karnataka the incidence of awareness regarding eye donation was reported to be $96 \%$. However the difference was the age of the respondents. While the average age of the respondents in the study carried out by Priyadarshini B was 55years(Priyadarshini et al., 2003), the similar study carried out by Nekar in Hubli was an awareness study among college students aged between 18-26years old by this study they came to know that the awareness level greater in a younger age(Nekar et al., 2012).In the present study 59\% those who were aware of eye donation were below the age of 30 years.

\section{CONCLUSION}

Most of the students these days were aware of organ and body donation and they show a responsible attitude towards these procedures. But, there exist a circle of students who were not aware of organ and body donation. Even the certain group of medical and dental students don't have basic knowledge about organ and body donation and they have a lethargic attitude of gaining some knowledge about the topic. It is therefore essential to give importance to organ and body donation and this could be successfully done by incorporating these topics in curriculum.

\section{ACKNOWLEDGEMENTS}

With Sincere gratitude, we acknowledge the staff members of the department of Anatomy and Saveetha dental college and study participants for their extended support towards the completion of research.

Conflict of interest: declared as none.

\section{REFERENCES}

Afzali, B., Lechler, R. and Lombardi, G. (2015) 'Graft Rejection: Immunological Suppression', eLS, pp. 1-9. doi: 10.1002/9780470015902.a0001231.pub3.

Ahlert, M. and Sträter, K. F. (2020) '[Attitudes towards organ donation in Germany: Qualitative analyses supplementing quantitative evidence]', Zeitschrift fur Evidenz, Fortbildung und Qualitat im Gesundheitswesen. doi: 10.1016/j.zefq.2020.05.008.

Akbulut, S. et al. (2020) 'Attitudes, awareness, and knowledge levels of the Turkish adult population toward organ donation: Study of a nationwide survey', World journal of clinical cases, 8(11), pp. 2235-2245.

Alan, C. and Kurt, H. A. (2019) 'ORGAN DONATION AWARENESS', Journal of Scientific Perspectives, pp. 59-62. doi: 10.26900/jsp.3.009.

Al-Khafaji, A. B. (2017) 'OBSOLETE: Ethics of Organ Transplants', Reference Module in Biomedical Sciences. doi: 10.1016/b978-0-12-801238-3.98830-5.

Allen, M. D. and Stillwater, B. (no date) 'Organ Donation and Transplantation', Understanding Organ Donation, pp. 83-97. doi: 10.1002/9781444317459.ch5.

Bashir, J. (2017) 'A descriptive survey to assess the awareness on organ donation among students', Scientific Journal of India, pp. 27-28. doi: 10.21276/24565644/2017.v2.i1.11.

Bhamidimarri, K. R. (2014) Liver Transplantation: Update of Concepts and Practice, An Issue of Clinics in Liver Disease,. Elsevier Health Sciences.

Boscolo-Berto, R. et al. (2020) 'Body donation in Italy: Lights and shadows of law No. 10/2020', Clinical anatomy . doi: 10.1002/ca.23623. 
Busker, A. E. (1988) Immunological mechanisms of chronic graft rejection.

Busuttil, R. W. and Klintmalm, G. B. (2015) Transplantation of the Liver. Saunders.

Choudhari, S. and Thenmozhi, M. S. (2016) ‘Occurrence and Importance of Posterior Condylar Foramen', Research Journal of Pharmacy and Technology, p. 1083. doi: 10.5958/0974-360x.2016.00206.7.

Copeman, J. (2006) 'Cadaver Donation as Ascetic Practice in India', Social Analysis. doi: 10.3167/015597706780886085.

Critchley, W. R. and Fildes, J. E. (2012) 'Graft rejection endogenous or allogeneic?', Immunology, pp. 123-132. doi: 10.1111/j.1365-2567.2012.03560.x.

Fan, S. T., Chiu, A. and Hui, T. W. (2011) Living Donor Liver Transplantation. World Scientific.

Ganikos, M. (no date) ‘Organ Donation', Understanding Organ Donation, pp. 13-39. doi: 10.1002/9781444317459. ch2.

Gulec, B. (2011) 'Ischemia Reperfusion Injury in Kidney Transplantation', Kidney Transplantation - New Perspectives. doi: 10.5772/18289.

Hafeez, N. and Thenmozhi (2016) 'Accessory foramen in the middle cranial fossa', Research Journal of Pharmacy and Technology, p. 1880. doi: 10.5958/0974360x.2016.00385.1.

Humar, A. and Tevar, A. (2018) Liver Transplantation: State of the Art. World Scientific Publishing.

Hutchinson, E. F. et al. (2020) 'The Law, Ethics and Body Donation: A Tale of Two Bequeathal Programs', Anatomical sciences education, 13(4), pp. 512-519.

Ismail, A. S. B., Lim, K. G. and Mahadevan, D. T. (2020) 'Knowledge, attitude and factors influencing public willingness towards organ donation among hospital patients and relatives in Negeri Sembilan, Malaysia', The Medical journal of Malaysia, 75(3), pp. 260-265. Johnson, J. et al. (2020) 'Computational identification of MiRNA-7110 from pulmonary arterial hypertension (PAH) ESTs: a new microRNA that links diabetes and PAH', Hypertension research: official journal of the Japanese Society of Hypertension, 43(4), pp. 360362.

Kannan, R. and Thenmozhi, M. S. (2016) 'Morphometric Study of Styloid Process and its Clinical Importance on Eagle's Syndrome', Research Journal of Pharmacy and Technology, p. 1137. doi: 10.5958/0974360x.2016.00216.x.

Keerthana, B. and Thenmozhi, M. S. (2016) 'Occurrence of foramen of huschke and its clinical significance', Research Journal of Pharmacy and Technology, p. 1835. doi: 10.5958/0974-360x.2016.00373.5.

Krishna, R. N., Nivesh Krishna, R. and Yuvaraj Babu, K. (2016) 'Estimation of stature from physiognomic facial length and morphological facial length', Research Journal of Pharmacy and Technology, p. 2071. doi: 10.5958/0974-360x.2016.00423.6.

Krucinska, B. et al. (2020) 'Assessment of Knowledge and Attitudes Toward Transplantation Among Nursing Students', Transplantation proceedings. doi: 10.1016/j. transproceed.2020.03.007.

Kumar, P., Kanvinde, H. and Thomas, M. (2018) 'Impact of Training Volunteers for Creating Awareness on Organ Donation', Transplantation, pp. S814-S815. doi: 10.1097/01.tp.0000543855.18363.92.

Liver Transplantation' (2016). doi: 10.1002/lt.v22.5.

Magotra, R. (2014) 'Organ donation: awareness a must', Indian Journal of Medical Ethics. doi: 10.20529/ ijme.2014.032.

Mannis, M. J. (2004) ‘Corneal Transplantation', Cornea, p. 321. doi: 10.1097/00003226-200404000-00023.

Menon, A. and Thenmozhi, M. S. (2016) 'Correlation between thyroid function and obesity', Research Journal of Pharmacy and Technology, p. 1568. doi: 10.5958/0974-360x.2016.00307.3.

Nandhini, J. S. T. et al. (2018) 'Size, Shape, Prominence and Localization of Gerdy's Tubercle in Dry Human Tibial Bones', Research Journal of Pharmacy and Technology, p. 3604. doi: 10.5958/0974-360x.2018.00663.7.

Nekar, M. S. et al. (2012) 'AWARENESS OF EYE DONATION AMONG COLLEGE STUDENTS OF HUBLI CITY, KARNATAKA', International Journal of Biomedical Research. doi: 10.7439/ijbr.v3i4.415.

Organ Donation and Transplantation: Awareness and Roles of Healthcare Professionals-A Systematic Literature Review (2018).

Organ Transplants and Ethics' (1992) Philosophical Books, pp. 47-48. doi: 10.1111/j.1468-0149.1992. tb02325.x.

Orlando, G., Remuzzi, G. and Williams, D. F. (2017) Kidney Transplantation, Bioengineering, and Regeneration: Kidney Transplantation in the Regenerative Medicine Era. Academic Press.

Patwardhan, S. S. and Kulkarni, G. V. (2011) 'Improving the rates of cadaver organ donation in a tertiary care transplant centre: a role for medical students and ancillary staff', Journal of postgraduate medicine, 57(4), pp. 347-349.

Petechuk, D. (2006) Organ Transplantation. Greenwood Publishing Group.

Ponticelli, C. (2007) Medical Complications of Kidney Transplantation. CRC Press.

Ponziani, F. R. et al. (2020) 'Effect of liver transplantation on intestinal permeability and correlation with infection episodes', PloS one, 15(6), p. e0235359.

Pratha, A. A., Ashwatha Pratha, A. and Thenmozhi, M. S. (2016) 'A Study of Occurrence and Morphometric Analysis on Meningo Orbital Foramen', Research Journal of Pharmacy and Technology, p. 880. doi: 10.5958/0974-360x.2016.00167.0.

Priyadarshini, B. et al. (2003) 'Awareness of eye donation in an adult population of southern India. A pilot study', Indian journal of ophthalmology, 51(1), pp. 101-104. Rinehardt, H. N. et al. (2020) 'Successful Liver Transplantation for Adolescent Patient With Pyruvate 
Kinase Deficiency-induced Cirrhosis', Journal of pediatric hematology/oncology. doi: 10.1097/ MPH.0000000000001876.

Samuel, A. R. and Thenmozhi, M. S. (2015) 'Study of impaired vision due to Amblyopia', Research Journal of Pharmacy and Technology, p. 912. doi: 10.5958/0974360x.2015.00149.3.

Sarti, A. (1999) 'Organ donation', Pediatric Anesthesia, pp. 287-294. doi: 10.1046/j.1460-9592.1999.00390.x.

Schwartz, T. P. (2005) Organ Transplants: A Survival Guide for the Entire Family : the Ultimate Teen Guide. Rowman \& Littlefield.

Sekar, D. et al. (2019) 'Methylation-dependent circulating microRNA 510 in preeclampsia patients', Hypertension Research, pp. 1647-1648. doi: 10.1038/ s41440-019-0269-8.

Seppan, P. et al. (2018) 'Therapeutic potential of Mucuna pruriens (Linn.) on ageing induced damage in dorsal nerve of the penis and its implication on erectile function: an experimental study using albino rats', The Aging Male, pp. 1-14. doi: 10.1080/13685538.2018.1439005.

Singh, R. and Tripathy, K. (2016) 'Is Transplantation of Cornea Obtained From a Septicemic Donor Safe?', Cornea, p. e25. doi: 10.1097/ico.0000000000000959. Siripurapu, S. and Vijay Kumar Sharma, M. (2018) 'An Analysis Upon Various Developments of Human
Cadaver Organ Donation and Transplantation In India', Journal of Advances and Scholarly Researches in Allied Education, pp. 111-116. doi: 10.29070/15/57807.

Sriram, N., Thenmozhi and Yuvaraj, S. (2015) 'Effects of Mobile Phone Radiation on Brain: A questionnaire based study', Research Journal of Pharmacy and Technology, p. 867. doi: 10.5958/0974-360x.2015.00142.0.

Subashri, A. and Thenmozhi, M. S. (2016) 'Occipital Emissary Foramina in Human Adult Skull and Their Clinical Implications', Research Journal of Pharmacy and Technology, p. 716. doi: 10.5958/0974360x.2016.00135.9.

Thejeswar, E. P. and Thenmozhi, M. S. (2015) 'Educational Research-iPad System vs Textbook System', Research Journal of Pharmacy and Technology, p. 1158. doi: 10.5958/0974-360x.2015.00208.5.

Toledo-Pereyra, L. H. (2012) Pancreas Transplantation. Springer Science \& Business Media.

Troppmann, C. (2020) 'Medical complications after pancreas transplantation', Transplantation, Bioengineering, and Regeneration of the Endocrine Pancreas, pp. 239-246. doi: 10.1016/b978-0-12814833-4.00020-4.

Tsoulfas, G. (2018) Organ Donation and Transplantation: Current Status and Future Challenges. BoD - Books on Demand. 